\title{
Application of Failure Criteria in Aeronautical Sandwich Structure Composites with a Central Hole Subjected to Bending Testing
}

\author{
Franciélio Gomes da Silva ${ }^{a}$ (D), Raimundo Carlos Silverio Freire Júnior ${ }^{a *}$ (D), \\ Selma Hissae Shimura da Nobrega $a^{a}$ (D), Avelino Manuel da Silva Dias ${ }^{a}$ (D)

\begin{abstract}
${ }^{a}$ Universidade Federal do Rio Grande do Norte, Centro de Tecnologia, Programa de Pós-Graduação em Engenharia Mecânica, Lagoa Nova, CEP: 59072-970, Natal, Rio Grande do Norte, Brasil
\end{abstract}

Received: January 21, 2020; Revised: April 01, 2020; Accepted: April 14, 2020

\begin{abstract}
This study aimeds at investigating the mechanical behavior of an E-glass fiber-reinforced epoxy resin of a laminated composite sandwich with honeycomb core and a central hole, used in the aeronautics industry submitted to bending loading. Three analytical failure models applied to laminated composites were compared in order to study the influence of stress concentration due to a central hole. The following criteria were assessed: Average Stress Criterion (ASC), Point Stress Criterion (PSC) and the Inherent Flaw Model (IFM). These models were applied to experimental data obtained in a four-point bending test in samples of the sandwich laminate. Finally, modifications on failure prediction models were proposed and appied in sandwich laminates with a central hole. The results obtained showed the applicability of the proposed formulation and that the suggested changes to the model more adequately fit it to the experimental data.
\end{abstract}

Keywords: Aeronautical Sandwich Composites, Failures Models, Bending Test.

\section{Introduction}

Many modern technologies require materials with uncommon combinations of properties that cannot be achieved by a single material. The combinations and the range of material properties are constantly evolving with the development of composite materials. The aeronautic and aerospace industries have used an enormous amount of composite materials in their products, particularly laminated composites. However, these composites pose a challenge in devising methods to predict mechanical strength, primarily when they exhibit stress concentrations.

The laminated composite category includes a wide range of materials, from the most common place to the sophisticated. Glass, carbon and aramid fibers are among the most common reinforcement materials in these composites, and the aeronautic and aerospace industries have driven a large part of their development ${ }^{1}$.

Within this category of laminated composites are sandwich structures, which consist of two faces of a high-strength laminate separated by a low-density core with a honeycomb structure. The function of these two faces in the sandwich composite is to resist tensile and compression stresses on its opposite faces when the panel is submitted to external bending forces. They are also thick enough to withstand buckling and failures caused by localized impacts ${ }^{2}$. The sandwich laminated composite under study was manufactured with Fibrelam $^{\circledR}$ panels (Hexcel Composites), consisting of two thin unidirectional layers of E-glass fiber impregnated with F-155 epoxy resin containing fiber volume of $34 \%$ in the

*e-mail: freirej@ufrnet.br laminates and separated by a honeycomb core of phenolic resin, which exhibits low stiffness.

The most widely used methods for optimal preliminary design of laminates with stress concentrations are the Point Stress Criterion (PSC) and Average Stress Criterion (ASC) proposed by Whitney and Nuismer, or their variations $\mathrm{s}^{3-5}$. The PSC assumes that failure occurs when the stress at a characteristic distance from the hole or notch edge reaches the tensile strength of an unnotched material. The ASC predicts failure when the average stress over a characteristic distance is equal to the unnotched strength. Recent research has reported several methods, such as the IFM and finite fracture mechanics (FFM) model ${ }^{5-7}$. However, all of these methods have been applied to study laminate composites with stress concentrations that underwent tensile strength testing ${ }^{8}$. No study was found that used these methodologies to sandwich-laminated composites design, when submitted to bending forces.

This study conducted four-point bending testing in sandwich laminate plate samples with a central hole to determine bending resistance, modulus of elasticity in bending and flexural strain. After load behavior as a function of strain was determined for this bending test, the PSC, ASC and the IFM were used to study the applicability of these failure criteria.

Finally, in addition to the cases studied, these failure prediction models were modified in order to apply them in sandwich laminates with a central hole. The results obtained show the applicability of the proposed formulation in the study of laminates with stress concentrations submitted to bending. 


\section{Methodology}

The composite was studied at the behest of the ALLTEC Company, located in São Jose dos Campos, São Paulo, Brazil. Two Fibrelam ${ }^{\circledR}$ sandwich laminated plates (Hexcel Composites) were acquired, with two unidirectional E-glass fiber laminas, impregnated with F-155 epoxy resin, containing fiber volume of $34 \%(V)$ in the laminas and separated by a honeycomb core of phenolic resin $(355 \mathrm{~mm}$ wide by $1835 \mathrm{~mm}$ long). This material is used in the construction of aircraft components such as floor and ceiling reinforcement.

The panels manufactured using an autoclave, exhibit excellent quality, with total $(h)$ and core $(c)$ thickness of 10.8 and $9.8 \mathrm{~mm}$, respectively.

For the present study, ASTM standard code C393 (2016) was used as reference ${ }^{9}$. A four-point bending tests were carried out, with and without a hole, as shown in Figure 1. The specimens were tested with the fibers parallel to their length $(300 \mathrm{~mm})$. The width $(W)$ of the test specimens without a hole was $75 \mathrm{~mm}$ and those with a hole had the following combinations of width $(W)$ and diameter $(D)$, in mm: W75D16, W75D22, W85D14, W90D16, W90D22, W90D32 and W90D38 (Table 1). These combinations were selected in order to increase the region of experimental data analysis when related to the failure criteria studied here and to make better use of the material.

During the tests, a length of $250 \mathrm{~mm}$ between supports $(S)$ was used and a distance of $83 \mathrm{~mm}(S / 3)$ from the support to the load application lines (Figure 2). A total of 43 tests were conducted, with five samples for each width/diameter combination and eight samples for the laminate without a hole. All the tests were carried out in a Shimadzu universal testing machine with maximum capacity of $300 \mathrm{kN}$.

To calculate the flexural modulus $\left(E_{l}\right)$ and bending stress on the face $(\sigma)$ of the material, Equations 1 and 2 from ASTM
C393 (2016) and ASTM 7249 (2016), respectively, were used ${ }^{9,10}$. In these expressions, $P$ is the applied load, $S$ is the span, $t$ is the ply thickness, $c$ is the core thickness, and $h$ is the total sandwich thickness. $\varepsilon_{3000}, \varepsilon_{1000}, \sigma_{3000}$ and $\sigma_{1000}$ are the strains and stresses corresponding to 3,000 and 1,000 micro-strain, respectively. It is noteworthy that Equation 2 was used to calculate ultimate strength on the face of the material with $\left(\sigma_{N}\right)$ and without a hole $\left(\sigma_{0}\right)$.

$$
\begin{gathered}
E_{l}=\frac{\sigma_{3000}-\sigma_{1000}}{\left(\varepsilon_{3000}-\varepsilon_{1000}\right)((c+t) /(c+2 t))} \\
\sigma=\frac{P S}{3 t(h+c) W}
\end{gathered}
$$

In addition to the modulus of elasticity $\left(E_{1}\right)$, Poisson's ratio $\left(v_{12}\right)$ was measured using rosette extensometers at $90^{\circ}$. Figure 2 demonstrates the test scheme and Table 2 the results obtained for the sandwich laminate without a hole. It is important to say that the sandwich composite behavior was linear throughout the test, both for the material without notch and for the notched material. In addition to the experimental values obtained $\left(\sigma_{0}, E_{1}, v_{12}\right)$, Table 2 also presents the transverse

Table 1. Nomenclature used to samples.

\begin{tabular}{ccc}
\hline Nomenclature & Width $(\mathrm{W})$ & Diameter $(\mathrm{D})$ \\
\hline W75D16 & $75 \mathrm{~mm}$ & $16 \mathrm{~mm}$ \\
\hline W75D22 & $75 \mathrm{~mm}$ & $22 \mathrm{~mm}$ \\
\hline W85D14 & $85 \mathrm{~mm}$ & $14 \mathrm{~mm}$ \\
\hline W90D16 & $90 \mathrm{~mm}$ & $16 \mathrm{~mm}$ \\
\hline W90D22 & $90 \mathrm{~mm}$ & $22 \mathrm{~mm}$ \\
\hline W90D32 & $90 \mathrm{~mm}$ & $32 \mathrm{~mm}$ \\
\hline W90D38 & $90 \mathrm{~mm}$ & $38 \mathrm{~mm}$ \\
\hline
\end{tabular}

(a)

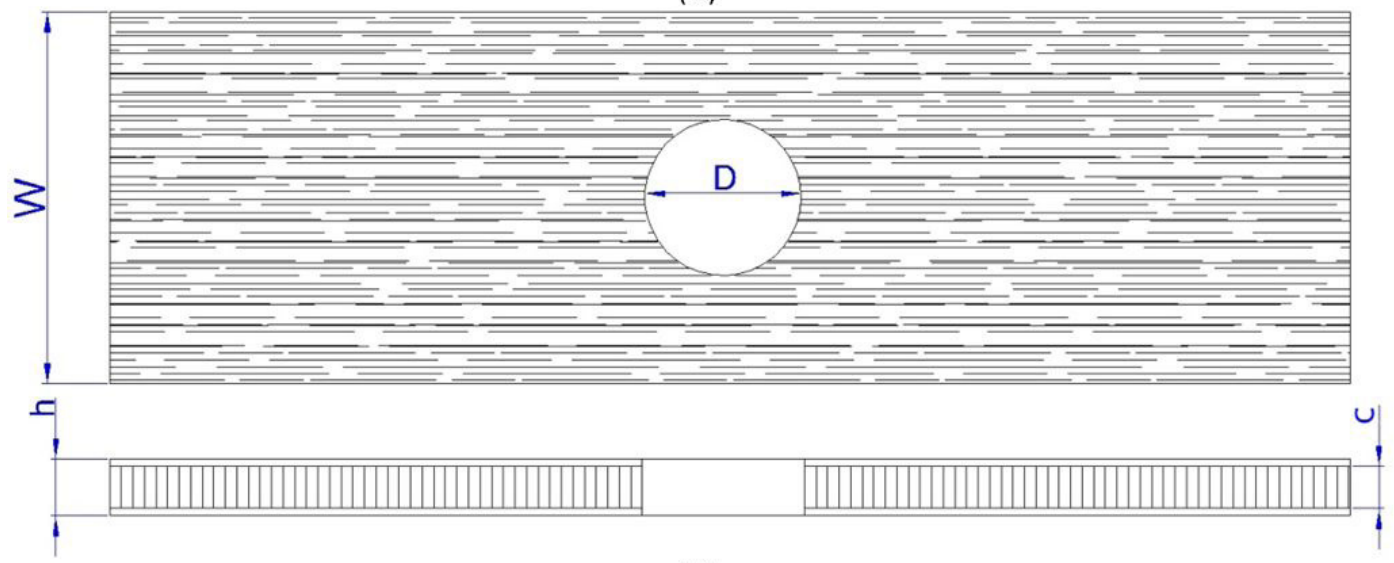

(b)

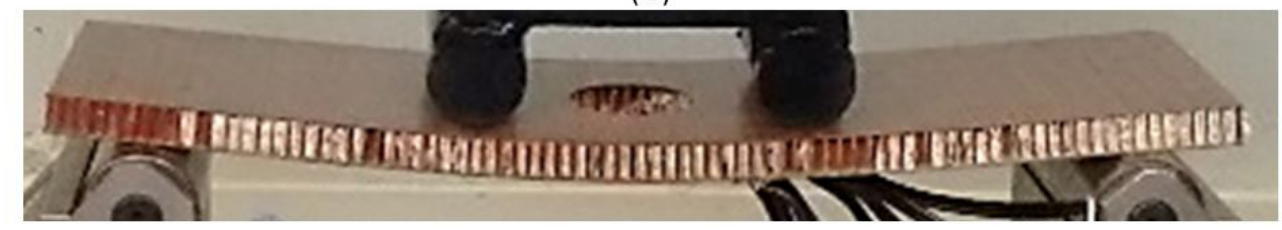

Figure 1. Test specimen of a sandwich laminate with a hole for the four-point bending testing (a) Schematic representation (b) Test Specimen. 


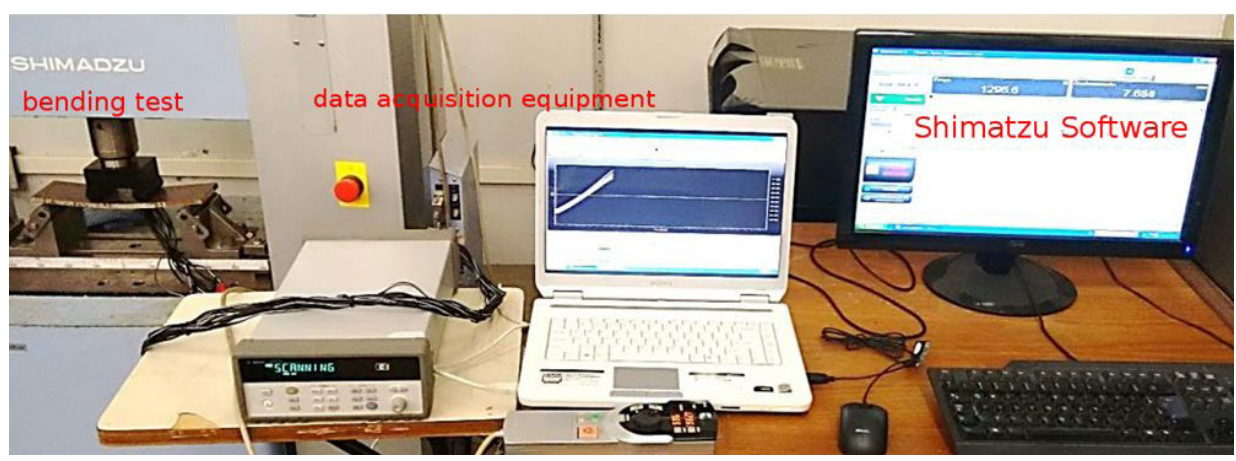

Figure 2. Four-point bending test in the sandwich laminate.

Table 2. Mechanical properties of the sandwich laminate.

\begin{tabular}{cccccc}
\hline$\sigma_{0}(\mathrm{MPa})$ & $E_{1}(\mathrm{GPa})$ & $v_{12}$ & $E_{2}(\mathrm{GPa})$ & $G_{12}(\mathrm{GPa})$ & $K_{T}^{\infty}$ \\
\hline $243 \pm 14$ & $25.6 \pm 0.5$ & $0.112 \pm 0.003$ & 6.8 & 2.4 & 4.8 \\
\hline
\end{tabular}

modulus of elasticity $\left(E_{2}\right)$, shear modulus $\left(G_{12}\right)$ and the stress concentration factor for an infinite plate $\left(K_{T}^{\infty}\right)$. The values of $E_{2}$ and $G_{12}$ were obtained by the Halpin-Tsai expressions, demonstrated in Equation 3 and $K_{T}^{\infty}$ by Equation $4^{11,12}$.

$$
\begin{gathered}
\frac{P}{P_{m}}=\frac{1+\xi \eta V_{f}}{1-\eta V_{f}}, \eta=\frac{P_{f} / P_{m}-1}{P_{f} / P_{m}+\xi} \\
K_{T}^{\infty}=1+\sqrt{\left\{2\left[\sqrt{\left(\frac{E_{I}}{E_{2}}\right)}-v_{12}\right]+\frac{E_{1}}{G_{12}}\right\}}
\end{gathered}
$$

In Equation 3, $P$ can be substituted by $E_{2}$ or $G_{12}, P_{m}$ is the value of the matrix modulus $\left(E_{m}=3.0 \mathrm{GPa}, G_{m}=1.3 \mathrm{GPa}\right)$ and $P_{f}$ is the value of the fiber modulus $\left(E_{f}=71 \mathrm{GPa}, G_{f}=29 \mathrm{GPa}\right)$. The best-fit factor was $\xi=2$ used to calculate $E_{2}$ and was equal one to calculate $G_{12}$.

It is important to highlight that, despite the fact that Equations 4 to 16 were used to analyze failure behavior in composites under tension or compression (and not bending), these equations will be used here to determine their viability. The laminate under study is symmetrical and has only one thin layer of E-glass fiber in the outer layers, which simplifies analysis (in this layer the shear stresses can be considered nil and these lamina will only be submitted to tension or compression and the honeycomb stiffness can be neglected).

Furthermore, the failure obtained with a hole always occurred in the region with the smallest width and consequently greatest stress. None of the samples exhibited displacement between the laminae and honeycomb, or localized damage only in the honeycomb.

\section{Analytical Prediction of Notched Strength}

Loadings in an infinite plate were considered to create a failure criterion model in the presence of a stress gradient (in this case due to the presence of hole). In this situation, there is an infinite orthotropic plate containing a circular hole with radius $R$, submitted to uniform stress $\left(\sigma^{\infty}\right)$ applied perpendicularly to the $\mathrm{x}$-axis, and longitudinal stress distribution $\left(\sigma_{y}\right)$ along the $\mathrm{x}$-axis ahead of the hole, expressed by Equation $5^{12}$.

$$
\frac{\sigma_{y}}{\sigma^{\infty}}=\frac{1}{2}\left\{2+\left(\frac{R}{x}\right)^{2}+3\left(\frac{R}{x}\right)^{4}-\left(K_{T}^{\infty}-3\right)\left[5\left(\frac{R}{x}\right)^{6}-7\left(\frac{R}{x}\right)^{8}\right]\right\}
$$

However, although stress analyses are conducted considering infinite plates, they cannot be performed in practice. Thus, an expression that serves as a correction factor for an infinite plate (FWC - finite width correction factor) was used, as demonstrated in Equation 6 and $7^{13,14}$. Equation 8 relates stress in a finite $(\sigma)$ and infinite plate $\left(\sigma^{\infty}\right)$.

$$
\begin{gathered}
\frac{1}{F W C}=\frac{3(1-D / W)}{2+(1-D / W)^{3}}+\frac{1}{2}\left(M \frac{D}{W}\right)^{6}\left(K_{T}^{\infty}-3\right)\left[1-\left(M \frac{D}{W}\right)^{2}\right] \\
M=\frac{\sqrt{1-8\left[\frac{3(1-D / W)}{2+(1-D / W)^{3}}-1\right]}-1}{2(D / W)^{2}} \\
\sigma=\sigma^{\infty} / F W C
\end{gathered}
$$

There are other methods for calculating FWC besides the use of the analytical equation presented in Equation 6. Taheri-Behrooz and Bakhshan ${ }^{15}$ for example, used the finite element method, applying the Progressive failure analysis technique, for calculating FWC for laminates manufactured with fiberglass woven.

\subsection{Maximum stress criterion (MSC)}

This criterion defines the failure threshold for material that is totally fragile and therefore insensitive to the hole, or totally ductile, and totally sensitive to stress concentration ${ }^{5,16,17}$. Equations 9 and 10 represent these two situations, respectively.

$$
\begin{gathered}
\frac{\sigma_{N}}{\sigma_{0}}=1-\frac{D}{W} \\
\frac{\sigma_{N}}{\sigma_{0}}=\frac{1-D / W}{2+(1-D / W)^{3}}
\end{gathered}
$$

$D$ represents the diameter of the hole and $W$ the width of the specimen, $\sigma_{0}$ and $\sigma_{N}$ the ultimate bending stress on the face of the material without and with a hole, respectively. 


\subsection{Inherent Flaw Model (IFM)}

Based on linear elastic fracture mechanics ${ }^{18-20}$, this model assumes that there is a region of intense energy with characteristic length $a$, in which the critical stress intensity factor of an infinite plate $\left(K_{I C}\right)$ with a hole whose radius is $R$, is given by Equation $11^{5,17,21,22}$.

$$
K_{I C}=\sigma_{N}^{\infty} \sqrt{(\pi a)} f(a, R)
$$

Where $\sigma_{N}^{\infty}$ is the ultimate stress in an infinite plate and $f(a, R)$, a function that relates the characteristic length $a$ and the radius $R$ of the circle, which was determined by Bowie ${ }^{23}$ in Equation 12.

$$
f(a, R)=\frac{1}{2}\left(3-\frac{a}{R+a}\right)\left[1+1.243\left(1-\frac{a}{R+a}\right)^{3}\right]
$$

Considering the situation in which the infinite plate has no hole $(R=0)$ and substituting this value in Equation 12, we have $f(a, 0)=1$, and applying this result in Equation 11, we have the result presented in Equation 13. In this situation, the ultimate stress in an infinite plate $\left(\sigma_{N}^{\infty}\right)$ is equal to that of the finite plate $\left(\sigma_{0}\right)$, and by substituting this result in Equation 11, it can be demonstrated that the stress ratio between the infinite and finite plate is equal to 1 divided by $f(a, R)$ (Equation 14).

$$
\begin{gathered}
\sigma_{0}=\left.\sigma_{N}^{\infty}\right|_{R \rightarrow 0}=\frac{K_{I C}}{\sqrt{(\pi a)}} \\
\frac{\sigma_{N}^{\infty}}{\sigma_{0}}=\frac{1}{f(a, R)}
\end{gathered}
$$

Equation 14 establishes the variation in the residual strength of the material in the presence of a hole in an infinite plate, and Equation 8 can be used to convert its values to a finite plate. The characteristic length $a$ can be obtained interactively, relating the residual strength response obtained by Equation 14 with the residual resistance value obtained experimentally, and ASTM D5766 $6^{24}$ serves as the basis for this analysis. When several tests are carried out with a change in radius $(R)$ and width $(W)$, the mean $a$ value can be used.

\subsection{Average Stress Criterion (ASC) and Point Stress Criterion (PSC)}

Whitney and Nuismer (1974) proposed two failure criteria to predict stress at the hole of composite laminates containing circular holes ${ }^{3}$. As mentioned in the introduction, these are known as the point stress criterion (PSC) and average stress criterion (ASC). The PSC estimates that failure occurs when the point stress found in Equation 5 is equal to the ultimate stress of the laminate with no hole at a fixed characteristic distance $d_{0}$. With respect to ASC, failure occurs when the average stress value is equal to the ultimate stress of the laminate with no hole at a characteristic distance $a_{0}$. The ASC and PSC can be represented by Equations 15 and 16, respectively.

$$
\begin{aligned}
& \frac{\sigma_{N}^{\infty}}{\sigma_{0}}=\frac{2\left(1-\xi_{1}\right)}{2-\xi_{1}^{2}-\xi_{1}^{4}+\left(K_{T}^{\infty}-3\right)\left(\xi_{1}^{6}-\xi_{1}^{8}\right)}, \xi_{1}=\frac{R}{R+a_{0}} \\
& \frac{\sigma_{N}^{\infty}}{\sigma_{0}}=\frac{2}{2-\xi_{2}^{2}+3 \xi_{2}^{4}-\left(K_{T}^{\infty}-3\right)\left(5 \xi_{2}^{6}-7 \xi_{2}^{8}\right)}, \quad \xi_{2}=\frac{R}{R+d_{0}}
\end{aligned}
$$

As with IFM, the characteristic lengths $a_{0}$ and $d_{0}$ can be obtained interactively for each width $(W)$ and hole diameter $(D)$ combination. For the material investigated here, these values are presented in Table 3. As mentioned in item 2, the behavior obtained for the material was linear throughout the test, it is important to remember that if the material had a non-linear behavior, the methodology for the numerical analysis would be different ${ }^{25,26}$.

Based on these results, the graph in Figure 3 was created to compare failure methods MSC, IFM, ASC and PSC. The sandwich laminate submitted to bend testing showed a result within the failure region (assessed by the MSC method)

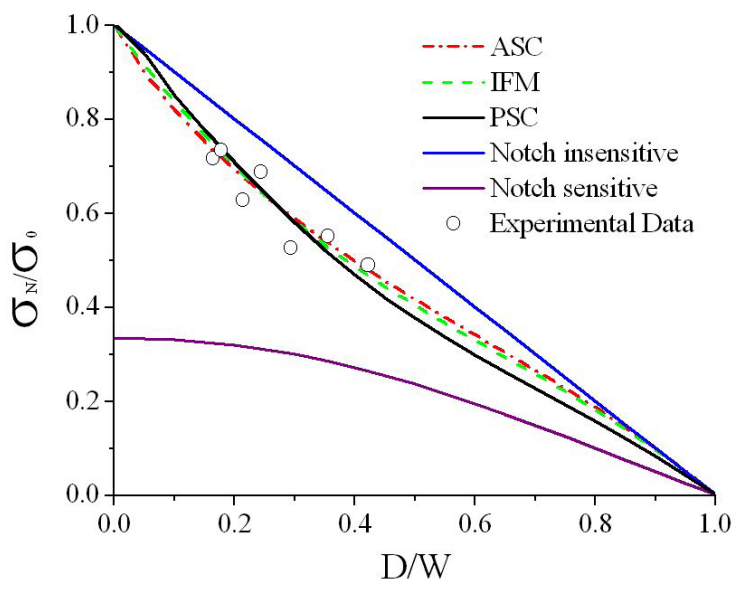

Figure 3. Comparison between experimental data and PSC, ASC, IFM and MSC criteria.

Table 3. Experimental data of the material with a hole and characteristic lengths $d_{0}, a_{0}$ and $a$.

\begin{tabular}{cccccccc}
\hline & $F W C$ & $\sigma_{N}(\mathrm{MPa})$ & $\sigma_{N}^{\infty}$ & $\sigma_{N}^{\infty} / \sigma_{0}$ & $d_{0}(\mathrm{~mm})$ & $a_{0}(\mathrm{~mm})$ & $a(\mathrm{~mm})$ \\
\hline W75D16 & 1.02 & 152.65 & 156.36 & 0.644 & 3.01 & 12.12 & 6.90 \\
\hline W75D22 & 1.05 & 127.87 & 134.08 & 0.552 & 3.06 & 10.76 & 6.50 \\
\hline W85D14 & 1.01 & 173.95 & 176.41 & 0.726 & 3.62 & 16.53 & 8.75 \\
\hline W90D16 & 1.02 & 178.27 & 181.22 & 0.746 & 4.60 & 21.65 & 11.22 \\
\hline W90D22 & 1.03 & 167.27 & 172.71 & 0.711 & 5.68 & 25.85 & 13.71 \\
\hline W90D32 & 1.07 & 133.95 & 144.04 & 0.593 & 5.52 & 21.54 & 12.48 \\
\hline W90D38 & 1.11 & 118.99 & 132.52 & 0.546 & 5.75 & 21.01 & 12.54 \\
\hline & & & Average & 4.46 & 18.50 & 10.3 \\
\hline
\end{tabular}


and exhibited a behavior closer to the notch-insensitive curve (Equation 9) than that of the notch-sensitive curve. Furthermore, the three methods are satisfactorily close to experimental data, where the ASC method displays the best correlation coefficient $(85.22 \%)$, followed by the IFM and PSC methods, with $84.92 \%$ and $84.44 \%$, respectively.

The average values obtained in Table 3 for each characteristic distance are very close to that observed for the W85D14 combination. This is important since ASTM D5766 $6^{24}$ uses a $D / W$ ratio of 0.166 , which is similar to the ratio of the combination tested (for W85D14, $D / W=0.165$ ). Thus, the result used in the ASTM standard can also be applied to the four-point bending test with a hole.

\subsection{IFM, ASC and PSC models as three-parameter linear models}

In order to improve the correlation between the aforementioned models and the experimental data, the three-parameter model was used to relate the characteristic length $\left(d_{0}, a_{0}\right.$ and $\left.a\right)$, represented by $l$, to an equation with $K_{F}$ and $m$ as constants to

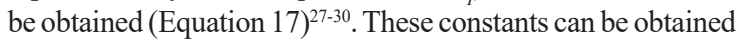
using the Newton-Raphson method ${ }^{31}$, and $m$ values must lie between 0 and 1 for the result to be valid.

$$
l=\frac{1}{\pi}\left(\frac{K_{F}}{\sigma_{0}}\right)^{2}\left(1-m \frac{\sigma_{N}^{\infty}}{\sigma_{0}}\right)^{2}
$$

For the sandwich laminate studied here, this model was not adequate, since the value of $m$ obtained by the three methods exhibited negative values. Thus, a model was created to improve the correlation between the failure criteria and experimental data, as demonstrated in the next item.

\subsection{Modifying PSC, ASC and IFM methods}

The results presented in Table 3 show that an increase in width always occurred with a rise in characteristic length, and that the ratio between thickness $(h)$ and width $(W)$ also influenced the residual bending strength of the material ${ }^{32}$.

Table 4. PSC, ASC and IFM constants obtained for Equation 18.

\begin{tabular}{ccc}
\hline & $A$ & $B$ \\
\hline$P S C$ & -101.28 & 16.87 \\
\hline$A S C$ & -478.44 & 77.12 \\
\hline$I F M$ & -249.82 & 40.86 \\
\hline
\end{tabular}

As such, a linear equation that relates the characteristic length $\left(d_{0}, a_{0}\right.$ and $\left.a\right)$ represented by $l$ with an $h / W$ ratio, was proposed in Equation 18.

$$
l=A \frac{h}{W}+B
$$

Where $l$ is the characteristic length $\left(d_{0}, a_{0}\right.$ and $\left.a\right)$ that depends on the method used, and $A$ and $B$ are the fit constants between the method and experimental data. Table 4 shows the values of $A$ and $B$ for each case.

Based on these results, new $\sigma_{N} / \sigma_{0}$ values can be calculated as a function of $h / W$ for each criterion and the determined correlation coefficients can be verified, as shown in Table 5 .

The three methods showed more accurate results than those exhibited in the previous items, increasing the correlation coefficient from $83 \%$ to $98 \%$. Furthermore, the PSC method produced the best result for this case.

It is important to emphasize that this method is not described in any of the articles researched ${ }^{3,6,33-37}$, and represents a new proposal in which the width and thickness of the analyzed specimens were considered.

Figures 4 to 6 were created to better analyze the curves formed by these three methods. In this case, rather than having a single curve for all the experimental values, we have a curve for each $h / W$ ratio, thereby obtaining more accurate results.

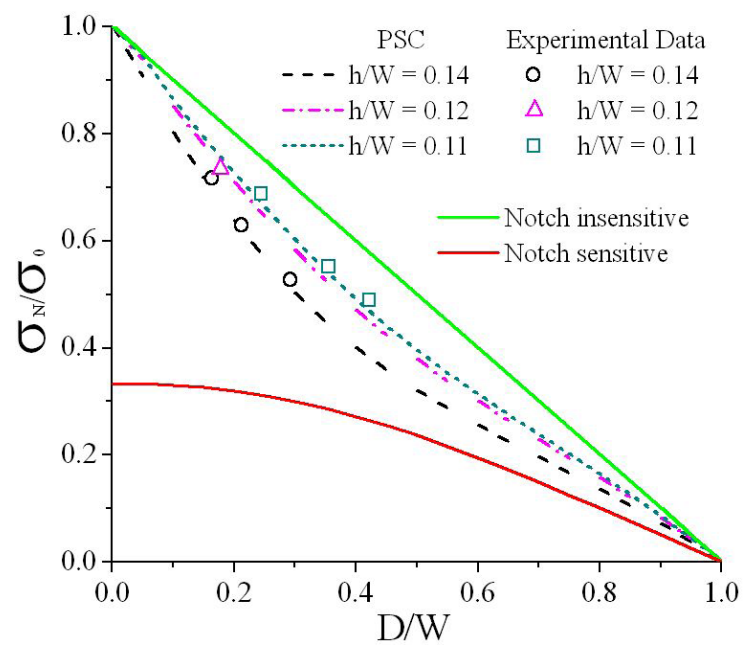

Figure 4. Comparison between the adapted PSC method proposed by Equation 18 and the experimental data.

Table 5. Residual stress ratio $\left(\sigma_{N}\right)$ in relation to stress on the material without hole $\left(\sigma_{0}\right)$ obtained from Equation 18 for the three methods (PSC, ASC and IFM) compared to the experimental values and their respective correlation coefficients.

\begin{tabular}{lcccc}
\hline & \multicolumn{2}{c}{$\sigma_{N} / \sigma_{0}$} & & $\sigma_{N} / \sigma_{0}$ \\
\cline { 2 - 4 } \cline { 5 - 5 } & Experimental & $P S C$ & $A S C$ & $I F M$ \\
\hline W75D16 & 0.628 & 0.618 & 0.611 & 0.612 \\
\hline W75D22 & 0.526 & 0.520 & 0.542 & 0.535 \\
\hline W90D16 & 0.716 & 0.748 & 0.721 & 0.733 \\
\hline W90D22 & 0.734 & 0.745 & 0.721 & 0.732 \\
\hline W90D32 & 0.689 & 0.665 & 0.657 & 0.658 \\
\hline W90D38 & 0.551 & 0.546 & 0.568 & 0.507 \\
\hline Correlation coefficient (\%) & 0.490 & 0.485 & 0.520 & 98.73 \\
\hline
\end{tabular}




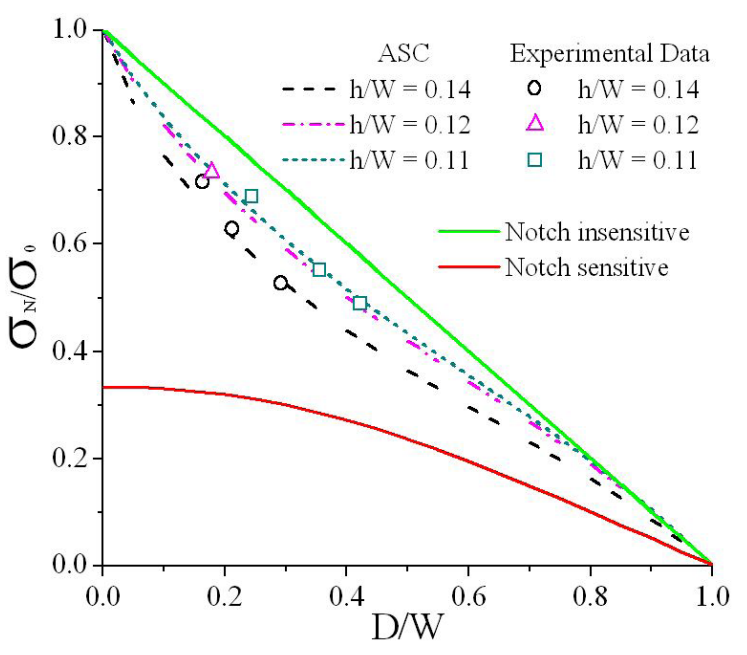

Figure 5. Comparison between the adapted ASC method proposed by Equation 18 and the experimental data.

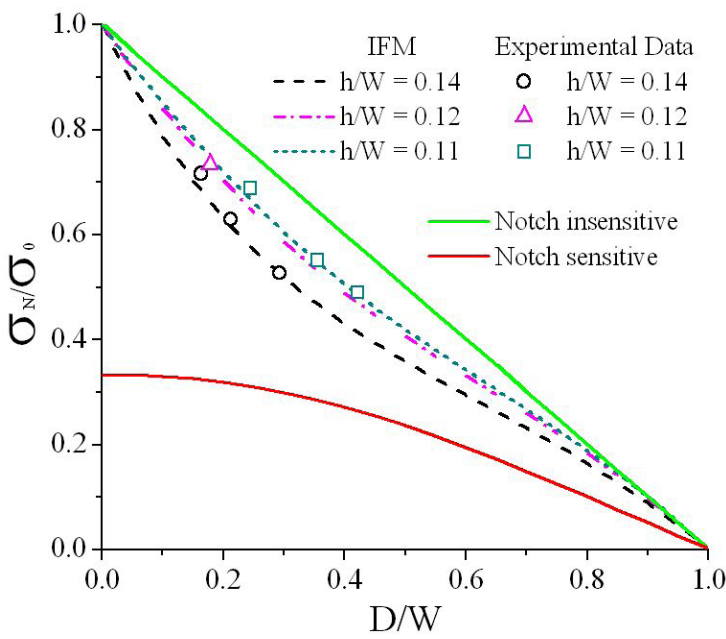

Figure 6. Comparison between the adapted IFM method proposed by Equation 18 and the experimental data.

\section{Conclusions}

Based on the results presented in previous topics, the following conclusions can be drawn:

- $\quad$ The maximum stress criterion (MSC) showed that the material is within the region of notch-sensitivity, but very close to the notch-insensitive curve.

- $\quad$ The PSC, ASC and IFM methods were successfully applied in the present study to analyze the sandwich composite under bending. The three methods satisfactorily represent the material under study, but the ASC method exhibited better correlation between the equation and experimental data.

- The average values of PSC, ASC and IFM characteristic length $\left(d_{0}, a_{0}\right.$ and $\left.a\right)$ was close to that of the $W 85 D 14$ configuration, corresponding to the same D/W ratio in ASTM D5766, suggesting that this ratio can also be applied to the four-point bending test.

- $\quad$ the $m$ values obtained in the PSC, ASC and IFM models with three parameters were all negative, so these model cannot be applied to this material.

- The relationship between width and characteristic length enabled the creation of an equation that better approximates the results of the three models (PSC, ASC and IFM) with the experimental data and increases the correlation coefficient from $83 \%$ to $98 \%$.

- In the present study, there was no delamination failure between the outer layers and their core during the bend test. The damage obtained in the samples with a hole always occurred in the region of greatest stress and smallest width.

\section{Acknowledgements}

The authors gratefully acknowledge the grants by CNPq (Brazilian Council for Scientific and Technological Development) and by CAPES - Finance Code 001 (Higher Coordination for Scientific and Educational Training).

\section{References}

1. Daniel IM, Ishai O. Engineering mechanics of composite materials. 2nd ed. Oxford: Oxford University Press; 2006.

2. Nasseh J. Manual de construção de barcos. 4th ed. Rio de Janeiro: Barracuda Advanced Composites; 2011.

3. Whitney JM, Nuismer RJ. Stress fracture criteria for laminated composite containing stress concentration. J Compos Mater. 1974;8:253-65.

4. Whitworth HA, Aluko O, Tomlinson NA. Application of the point stress criterion to the failure of composite pinned joints. Eng Fract Mech. 2008;75:1829-39.

5. Camanho PP, Erçin GHB, Catalanotti G, Mahdi S, Linde P. A finite fracture mechanics model for the prediction of the open-hole strength of composite laminates. Compos, Part A Appl Sci Manuf. 2012;43:1219-25.

6. Ercin H, Camanho PP, Xavier J, Catalanotti G, Linde P, Mahdi S. Size effects on the tensile and compressive failure of notched composite laminates. Compos Struct. 2013;96:736-44.

7. Anish AK. Ultimate strength analysis of laminated composite sandwich plates. Structures. 2018;14:95-110.

8. Khashaba UA, Khdair AI. Open hole compressive elastic and analysis of CFRE composites for aerospace applications. Aerosp Sci Technol. 2017;60:96-107.

9. ASTM: American Society for Testing and Materials. ASTM C393 -Standard Test Method for Core Shear Properties of Sandwich Constructions by Beam Flexure. Pennsylvania: ASTM; 2016.

10. ASTM: American Society for Testing and Materials. ASTM D7249 -Standard Test Method for Facing Properties of Sandwich Constructions by Long Beam Flexure. Pennsylvania: ASTM; 2016.

11. Halpin JC, Tsai SW. Effects of environmental factors on composite materials. In: Halpin JC, Air Force Materials Laboratory (U.S.). AFNL-TR-67-423. Ohio: Wright-Patterson Air Force Base, OH, Air Force Materials Laboratory, Air Force Systems Command; 1969.

12. Konish HJ, Whitney JM. Approximate stresses in an orthotropic plate containing a circular hole. J Compos Mater. 1975;9:15766.

13. Tan SC. Finite-width, correction factors for anisotropic plate containing a center opening. J Compos Mater. 1988;22:1080-97. 
14. Rubio-González C, Velasco F, Martinez J. Analysis of notched woven composites and fiber metal laminates with previous fatigue damage. J Compos Mater. 2016;50:885-97.

15. Taheri-Behrooz F, Bakhshan H. Characteristic length determination of notched woven composites. Adv Compos Mater. 2018;27:67-83.

16. Soutis C, Fleck NA. Failure prediction technique for compression loaded carbon fibre-epoxy laminate with notched. J Compos Mater. 1991;25:1476-98.

17. Camanho PP, Maimí P. Size effects on the strength of notched composites. In: Proceedings of the 16th ICCM Sixteenth International Conference on Composite Materials; 2007; Kyoto, Japan. Hoboken: JSCM; 2007.

18. Waddoups ME, Eisenmann JR, Kaminski BE. Macroscopic fracture mechanics of advanced composite materials. J Compos Mater. 1971;5:446-54.

19. Anderson TL. Fracture mechanics, fundamentals and applications. 3rd ed. New York: CRC Press Inc; 2005.

20. Nikishkov Y, Seon G, Makeev A, Shonkwiler B. In-situ measurements of fracture toughness properties in composite laminates. Mater Des. 2016;94:303-13.

21. Kannan VK, Rajadurai A, Rao BN. Residual strength of laminated composites after impact. J Compos Mater. 2011;45:1031-44.

22. Belmonte HMS, Manger CIC, Orin SL, Smith PA, Lewin R. Characterization and modeling of the notched tensile fracture of woven quasi-isotropic GFRP laminates. Compos Sci Technol. 2001;61:585-97.

23. Bowie OL. Analysis of an infinite plate containing radial cracks originating at the boundary of an internal circular hole. Stud Appl Math. 1956;35(1-4):60-71.

24. ASTM: American Society for Testing and Materials. ASTM D5766 - Standard test method for Open-Hole Tensile Strength of Polymer Matrix Composite Laminates. Pennsylvania: ASTM; 2016.

25. Fallari H, Taheri-Behrooz F, Asadi A. Nonlinear mechanical response of polymer matrix composites: a review. Polym Rev (Phila Pa). 2020;60:42-85.
26. Mansourinik M, Taheri-Behrooz F. The effect of interface debonding on flexural behaviour of composite sandwich beams. J Sandw Struct Mater. 2018; In press.

27. Kannan VK, Murali V, Rajadurai A, Rao BN. Tension and compression strength evaluation of composite plates with circular holes. J Reinf Plast Compos. 2010;29:1500-14.

28. Kannan VK, Murali V, Rajadurai A, Rao BN. Residual strength of laminated composites after impact. J Compos Mater. 2011;45:1031-44.

29. Potti PKG, Rao BN, Srivastava VK. A new approach in utilizing inherent flaw model for tensile fracture of composite laminates with a circular hole. Adv Compos Lett. 1999;8:119-31.

30. Potti PKG, Rao BN, Srivastava VK. Notched strength of carbon fiber/epoxy composite laminates with a circular hole. Forsch. Ingenieurwes. 2000;65:295-300.

31. Press WH, Teukolsky SA, Vetterling WT, Flannery BP. Numerical recipes: the art of scientific computing. 3rd ed. Cambridge: Cambridge University Press; 2007.

32. Budynas RG, Nisbett KJ. Shigley's mechanical engineering design. 10th ed. New York: McGraw-Hill Education; 2015.

33. Mittal ND, Jain NK. Effect of fiber orientation on stress concentration factor in a laminate with central circular hole under transverse static loading. Indian J Eng Mater Sci. 2008; $15: 452-8$.

34. Toubal L, Karama M, Lorrain B. Stress concentration in a circular hole in composite plate. Compos Struct. 2005;68:31-6.

35. Wu HC, Mu B. On stress concentrations for isotropic/orthotropic plates and cylinders with a circular hole. Composite: Part B. 2003;34:127-34.

36. Seng CT. Stress concentration in laminated composites. New York: CRC Press; 1994.

37. Awerbuch J, Madhukar MS. Notched strength of composite laminates: predictions and experiments - a review. J Reinf Plast Compos. 1985;4:159. 